\title{
On the bi-dimensionality of liquidity
}

\section{ROBERTO PASCUAL ${ }^{1}$, ALVARO ESCRIBANO ${ }^{2}$ and MIKEL TAPIA ${ }^{3}$}

${ }^{1}$ Departamento de Economía y Empresa, Universidad de las Islas Baleares. E-mail: rpascual@uib.es

${ }^{2}$ Departamento de Economía, Universidad Carlos III de Madrid-Georgetown University. E-mail: alvaroe @eco.uc3m.es

${ }^{3}$ Departamento de Economía de la Empresa, Universidad Carlos III de Madrid. E-mail:mtapia@emp.uc3m.es

Variations in overall liquidity can be measured by simultaneous changes in both immediacy costs and depth. Liquidity changes, however, are ambiguous whenever both liquidity dimensions do not reinforce each other. In this paper, ambiguity is characterized using an instantaneous time-varying elasticity concept. Several bi-dimensional liquidity measures that cope with the ambiguity problem are constructed. First, it is shown that bi-dimensional measures are superior since commonalities in overall liquidity cannot be fully explained by the common factors in one-dimensional proxies of liquidity. Second, it is shown that an infinitesimal variation in either market volatility or trading activity augments the probability of observing an unambiguous liquidity adjustment. Ambiguity strongly depends on the expected (deterministic) component of volatility.

Keywords: liquidity, measurement, immediacy, depth, elasticity, ambiguity, bi-dimensional

\section{INTRODUCTION}

A recurrent topic in microstructure research is the analysis of market liquidity. As noted by Black (1971) and Kyle (1985), if we consider a stock market with a continuous trading system and we take the level of market efficiency as given, liquidity could be measured by simultaneously considering both immediacy costs and depth. Despite this generally accepted bi-dimensionality, early theoretical microstructure work focus on immediacy costs (Ho and Stoll, 1981; Copeland and Galai, 1983; Glosten and Milgrom, 1985; Stoll, 1989). In these models, market depth is avoided by assuming constant-sized trades. Kyle's (1985) model and its generalizations (Kyle, 1989; Subrahmanyam, 1991) do consider the market depth dimension. Nonetheless, in these cases immediacy costs are ignored since market makers set a single liquidation price. To the best of our knowledge, there is no model dealing with the theoretical relationship between the two liquidity dimensions.

A similar paradox is found in early microstructure empirical studies, which devote a scant effort to the interaction between immediacy costs and depth. The focus changes with the work of Lee et al. (1993). Using a sample of NYSE listed 
stocks, Lee et al. show that specialists actively manage information asymmetry risk by adjusting both immediacy costs and market depth. They report that lower (higher) spreads are generally accompanied by higher (lower) depth; hence, they are dependent dimensions. This finding implies that definitive inferences about market liquidity are impossible analysing only immediacy costs or depth. Recent empirical studies point out the relevance of considering both dimensions simultaneously to measure the impact of policy decisions and information events on liquidity (Goldstein and Kavajecz, 2000a,b; Jones and Lipson, 2001; Chordia et al., 2001, and Corwin and Lipson, 2000). In all these papers, unambiguous inferences about liquidity are only possible if the changes in immediacy costs and depth reinforce each other. Liquidity unambiguously changes whenever immediacy costs and depth move in opposite directions or one of them changes and the other one remains constant.

This paper is a first approach to cope with this ambiguity. First, we encourage the development of liquidity proxies that combine both liquidity dimensions into a single scalar measure. We use a sort of instantaneous time-varying elasticity measure between immediacy costs and depth to define ambiguity in overall liquidity changes. We consider alternative bi-dimensional liquidity measures that capture simultaneous changes in both facets of liquidity. These measures are larger than zero whenever overall liquidity increases and smaller than zero whenever overall liquidity decreases. We argue that these bi-dimensional measures represent a feasible solution to deal with ambiguity under a predetermined rate of substitution between both facets of liquidity. Using an intra-daily panel data of NYSE-listed stocks, and following the methodology proposed by Hasbrouck and Seppi (2001), we find evidence of commonalities in liquidity using both the bi-dimensional measures of liquidity and the conventional measures of immediacy costs and depth. We report, however, that the commonalities in overall liquidity cannot be fully explained by the common factors in the one-dimensional proxies of liquidity. This result implies that short-term overall liquidity dynamics cannot be fully explained by the one-dimensional proxies.

Secondly, we study the determinants of an unambiguous change in overall liquidity using discrete choice models. Focus is on the incidence of volatility and trading activity changes on the probability of observing unambiguous changes in overall liquidity. It is shown that an infinitesimal increase/decrease in either market volatility or trading activity augments the probability of observing an unambiguous liquidity adjustment. In our sample, the average trade size is more useful in predicting unambiguous variations in overall liquidity than the volume traded and the number of trades. However, changes in volatility are far more important than variations in the trading intensity. Finally, it is shown that the impact of volatility changes on the probability of an unambiguous overall liquidity adjustment strongly depends on the expected component of the volatility change. Hence, heterogeneous expectations about future volatility changes among liquidity providers might be associated with ambiguity.

The paper proceeds as follows. Section 2 reviews the one-dimensional measures of liquidity, characterizes the unambiguous changes in overall liquidity, and proposes different bi-dimensional measures based on this characterization. Section 3 describes the dataset and reports some preliminary analyses. Section 4 analyses 
commonalities in overall liquidity and Section 5 studies the determinants of an unambiguous change in overall liquidity. Conclusions are detailed in Section 6.

\section{MEASURING LIQUIDITY}

The quoted bid-ask spread is the most commonly used proxy to quantify immediacy costs. The spread captures the costs of trading instantaneously at the specialist's quotes instead of introducing non-marketable limit orders. The economic value of such costs can be assessed by the relative spread, the ratio of the bid-ask spread to the quote midpoint. Empirical evidence has reported, however, that trades may achieve price improvements (Lee and Ready, 1991). Because the specialist exposes the orders to the crowd and does not automatically execute them against the posted quotes, better prices than those quoted by the specialist are attainable. The effective spread (Petersen and Fialkowski, 1993) captures the notion that if a price improvement occurs, the bid-ask spread would overestimate the immediacy costs. The effective spread is computed as $E F S_{t}=2\left|P_{t}-q_{t}\right|$, where $P_{t}$ is the transaction price and $q_{t}$ is the quote midpoint.

Market depth is usually computed as the total size at the best quotes. This quoted size may represent the specialist's own trading interest, the trading interest of the crowd and limit orders stored in the Display Book. Nonetheless, this measure does not necessarily reflect the effective market depth (Handa et al., 1999; Bacidore et al., 2002). In the same manner that the effective spread can be lower than the quoted spread, the effective depth can be larger than the quoted depth. Recently, Engle and Lange (2001) introduced a new depth measure called VNET. It could be understood as an 'ex-post' or 'realized' depth proxy. VNET is computed as the one-sided volume (excess of buyer or seller initiated trading volume) needed to move the midpoint of the quoted bid-ask spread by a minimum amount. The VNET is conceptually similar to the liquidity ratio of Kluger and Stephan (1997). ${ }^{1}$

Lee et al. (1993) points out the impossibility of making inferences about overall liquidity based solely on immediacy costs or depth analyses. As a result, the most recent empirical research tends to gather together one-dimensional measures of both facets of liquidity. In this paper, it is argued that one-dimensional measures of immediacy costs, even when we have them all together, are insufficient to guarantee unambiguous inferences about liquidity. Ambiguity appears when the variations in immediacy costs and depth do not reinforce each other. Figure 1 illustrates the ambiguity problem. Figure 1(a) represents the (normally) unobservable pricing schedules of both sides of the market, supply (ask) and demand (bid). In most empirical applications, only points $X$ and $Y$, the best prices and the quantities offered at these prices, can be observed. Assuming that either the ask function or the bid function moves, new best quotes posted at some point

${ }^{1}$ The liquidity ratio (LR) is just the ratio of accumulated trading volume to accumulated change in prices during a given period. It ignores whether volume is buyer or seller initiated. This measure is extremely sensitive: small changes in prices move the liquidity ratio to extremely high values. In our opinion, the sensitivity of prices to order flow is better captured using VNET and it has better properties. 
inside the shaded areas represent an unambiguous shift in liquidity. For example, Fig. 1(b) corresponds to an upward shift in the ask function that worsens liquidity; in $X_{1}$ the immediacy costs are greater and the quoted depth is lower than in $X$. For changes in the ask function that lead to points out of the shaded areas in Fig. 1(a), the direction of the liquidity shift is not unequivocally determined.

If the correlation between the two dimensions of liquidity were strongly negative, overall liquidity would always vary towards the shaded areas. Table 3 in Lee et al. (1993, p. 360) shows that the two dimensions are negatively correlated, but it also reports that ambiguous variations in liquidity are frequent. As an additional example, Goldstein and Kavajecz (2000a) conclude that the decimalization process in US markets has had an uncertain impact on liquidity, since a decrease in immediacy costs coincides with a decrease in market depth (see also Ahn et al., 1996). To date, microstructure researchers have not paid attention to these ambiguous situations.

A measure of overall liquidity would require capturing simultaneous changes in the two facets of liquidity and showing some consideration for the trade-off between immediacy costs and depth, holding liquidity constant, a sort of 'liquidity indifference curve', as indicated by an anonymous referee. Hence, the overall liquidity measure would need to shape the market 'marginal rate of substitution' between both dimensions of liquidity. Let us assume that depth and immediacy costs are perfect substitutes, in the sense that a $1 \%$ decrease in immediacy costs compensates the market from a 1\% decrease in market depth. Then Fig. 1(c) represents changes in liquidity relative to an initial level $L_{0}$. Shaded areas enclose new levels $L_{1}=\left(I C_{1}, D_{1}\right)$ implying unequivocal increases or decreases in overall liquidity.

Consider the relative change in both facets of liquidity, as represented in Equation 1:

$$
\zeta_{t}^{D, I C}=-\frac{\left(D_{t}-D_{t-1}\right) / D_{t-1}}{\left(I C_{t}-I C_{t-1}\right) / I C_{t-1}}
$$

This measure can be thought as an instantaneous time-varying elasticity between depth and immediacy costs (see Fig. 1(d)). Notice that when ambiguity is absent $\zeta_{t}^{D, I C}>0$ but when ambiguity occurs $\zeta_{t}^{D, I C}<0$. Moreover, when the variation in immediacy costs is proportional to the variation in market depth, $\left|\zeta_{t}^{D, I C}\right|$ is close to one. When the variations are completely disproportional, $\left|\zeta_{t}^{D, I C}\right|$ will be either close to zero or larger than one. Therefore, $\zeta_{t}^{D, I C}$ provides some relevant information to characterize the changes in overall liquidity. However, it is not a useful inference tool because it does not distinguish between liquidity improvements and declines, even when they are not ambiguous. Additionally, because of the usual features of financial time series, $\zeta_{t}^{D, I C}$ may result in a very unstable measure. Large jumps should be expected due to sudden variations in immediacy costs and (especially) in market depth. Finally, $\zeta_{t}^{D, I C}$ might not be defined for some $t$ because of zeros in the denominator. Zeros are possible during periods of stable immediacy costs conditions.

Consider an alternative bi-dimensional liquidity measure with the following properties: (1) if overall liquidity varies ambiguously, that is $\zeta_{t}^{D, I C}<0$, this 


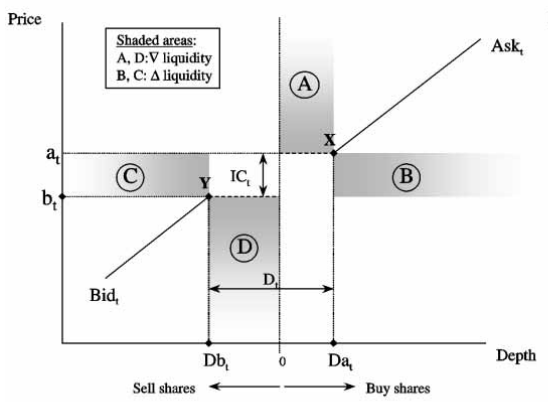

(a) The ambiguity problem.

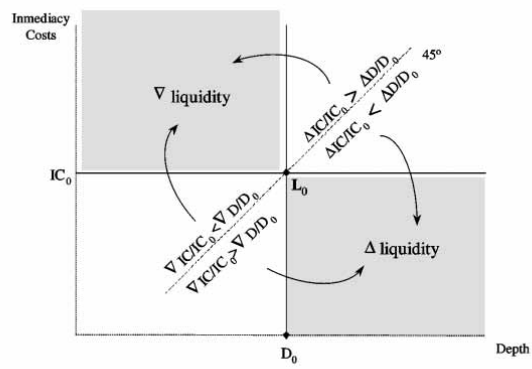

(c) Perfect substitutes .

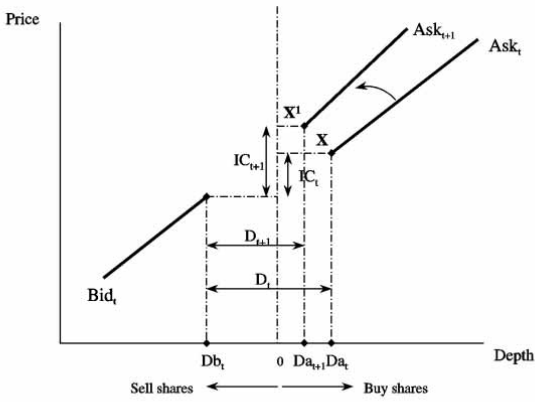

(b) Unambiguous liquidity decline.

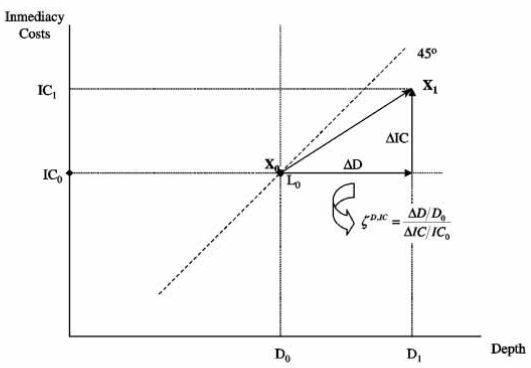

(d) Immediacy costs-depth elasticity.

Fig. 1. Ambiguity: (a) A movement of the ask price function to any point inside the shaded area $B$ or of the bid price function to the shaded area $C$, represents an unambiguous increase in liquidity. The remaining areas cover unclear variations in overall liquidity. (b) A change in the ask function leading to a decrease in liquidity. (c) Shaded areas represent unequivocal changes in liquidity with respect to the initial liquidity level $L_{t}$ under the assumption that immediacy costs and market depth are perfect substitutes. (d) The time-varying immediacy costs-depth elasticity characterizes ambiguity. Notation: $\Delta$ means 'increase' and $\nabla$ means 'decrease'.

measure reflects which facet of liquidity experiences a larger relative variation given a predetermined rate of substitution. In the case of perfect substitution, it approaches zero whenever both dimensions vary proportionally; it is positive whenever an increase (decrease) in market depth is larger (smaller) than a simultaneous increase (decrease) in immediacy costs, and it is negative otherwise. (2) When $\zeta_{t}^{D, I C}>0$, this measure is positive (negative) whenever overall liquidity improves (worsens). In the case of perfect substitution, the bi-dimensional measure in Equation 2 satisfies all these properties. Whenever $B L M_{t}>0$ overall liquidity improves, whenever $B L M_{t}<0$ it deteriorates, and whenever $B L M_{t}$ is close to zero, it does not change. This interpretation is independent of the sign of $\zeta_{t}^{D, I C}$.

$$
B L M_{t}=\frac{\Delta D_{t}}{D_{t-1}}-\frac{\Delta I C_{t}}{I C_{t-1}}
$$


A simple ratio of market depth to immediacy costs has already been used in some empirical studies (Bollen and Whaley, 1998; Kumar et al., 1998; Sarin et al., 1999; Gray et al., 2002). These studies do not deal with the ambiguity problem. Additionally, they do not show why this bi-dimensional measure outperforms one-dimensional measures. A measure, based on this ratio, comparable to $B L M_{t}$, is

$$
L R_{t}=\frac{D_{t}}{I C_{t}}-\frac{D_{t-1}}{I C_{t-1}}
$$

Notice that both $B L M_{t}$ and $L R_{t}$ approximate the idea of a relative variation given a predetermined rate of substitution. For example, a $1 \%$ increase or decrease in both facets of liquidity implies $B L M_{t}=0$ and $L R_{t}=0$. However, $L R_{t}$ has properties that are, a priori, less attractive. First, $L R_{t}$ is not a function of the instantaneous elasticity $\left(\zeta_{t}^{D, I C}\right)$. Second, $L R_{t}$ is less stable than $B L M_{t}$ and is dependent of measurement units. Third, both measures are linearly increasing in market depth and both measures are decreasing in immediacy costs. Nonetheless, $B L M_{t}$ is a linear function of immediacy costs and $L R_{t}$ is a non-linear (convex) one. Then, a $5 \%$ increase in market depth increases $L R_{t}$ more than a $5 \%$ decrease in immediacy costs, ceteris paribus, and the difference increases with the magnitude of the change.

Previous measures assume perfect substitution between both facets of liquidity. It can be argued, however, that due to market frictions, like the tick size, changes in immediacy costs are far more constrained than changes in market depth. A onetick change in the bid-ask spread is proportionally much greater than a 100 shares increase in market depth. This relative coarseness of the bid-ask spread also suggests that liquidity changes might be earlier detected in depths (Lee et al., 1993). Hence, the two facets of liquidity should not be equally responsive to variations in adverse selection costs, inventory holding costs or any other determinant of liquidity. This argument would have an immediate consequence on the required rate of substitution between immediacy costs and depth. For a $1 \%$ increase in immediacy costs, traders would remain in the same liquidity indifference curve only if market depth simultaneously increases by a percentage larger than $1 \%$. Consequently, any bi-dimensional liquidity measure should have an additional requirement: to account for the relative capacity of both liquidity dimensions to respond to any external stimulus. The measure in Equation 2 can be generalized as

$$
B L M(w)_{t}=\frac{\Delta D_{t}}{D_{t-1}}-w \frac{\Delta I C_{t}}{I C_{t-1}}
$$

where $w$ reflects a predetermined rate of substitution between both facets of liquidity. An immediate problem is how to determine $w$ objectively. We propose to use a measure of the relative variability of both facets of liquidity, say $w\left(\sigma_{t}^{I C}, \sigma_{t}^{D}\right)$. This measure would approximate the relative capacity of response of each dimension of liquidity. Therefore,

$$
B L M(\sigma)_{t}=\frac{\Delta D_{t}}{D_{t-1}}-\left(\frac{\sigma_{t}^{D}}{\sigma_{t}^{I C}}\right) \frac{\Delta I C_{t}}{I C_{t-1}}
$$

where $\sigma_{t}^{D}$ and $\sigma_{t}^{I C}$ are proxies of the volatility of each facet of liquidity in the earlier periods. Notice that Equation 5 allows for a time-varying rate of substitution. 
Finally, the measures proposed so far consider changes in liquidity relative to a reference level $L_{t-1}=\left(D_{t-1}, I C_{t-1}\right)$. It can be argued that these measures only capture short-term or transitory changes in overall liquidity, in particular when the time periodicity is short. A possible solution to this critique would be to consider a longer period of reference, say $A L_{t-n}^{t-1}=\left(A D_{t-n}^{t-1}, A I C_{t-n}^{t-1}\right)$, where $A D_{t-n}^{t-1}$ and $A I C_{t-n}^{t-1}$ are moving average measures of the previous values of the one-dimensional measures of liquidity,

$$
B L M(\mu, \sigma)_{t}=\frac{\left(D_{t}-A D_{t-n}^{t-1}\right)}{A D_{t-n}^{t-1}}-\left(\frac{\sigma_{t}^{D}}{\sigma_{t}^{I C}}\right) \frac{\left(I C_{t}-A I C_{t-n}^{t-1}\right)}{A I C_{t-n}^{t-1}}
$$

In this case, ambiguity can be redefined as any change in overall liquidity such that

$$
\zeta_{t}^{D, I C}(\mu)=-\frac{\left(D_{t}-A D_{t-n}^{t-1}\right) / A D_{t-n}^{t-1}}{\left(I C_{t}-A I C_{t-n}^{t-1}\right) / A I C_{t-n}^{t-1}}<0
$$

Notice that $B L M_{t}$ measures variations in liquidity supply for a given stock but does not inform one about the amount of liquidity provided. Therefore, this measure is more appropriate for time-series than for cross-sectional analyses. Nonetheless, given an initial liquidity level for each stock $L_{0}=D_{0}-I C_{0}$, the sum of posterior values of $B L M_{t}$ could proxy for the evolution of the amount of overall liquidity supply for each stock. Additionally, $B L M_{t}$ considers only the best market quotes and not the complete limit order book. Therefore, it is an instrument especially useful for 'small' (non-aggressive) traders. The entire set of offers of both sides of the market collectively provides the best visual representation of the liquidity supply. Nonetheless, limit order book data is not at hand in many professional and academic situations. For example, NYSE traders have a restricted access to the specialist's Display Book and the TAQ database, the official database of the NYSE, does not include limit order book data. Moreover, even if we could observe the entire limit order book, the ambiguity problem would still be present. Adding more layers of quotes to the database would complicate the definition of ambiguity and the computation of both market depth and immediacy costs, but the same inherent problem would persist. Recently, Martínez et al. (2000) and Irvine et al. (2000) proposed two equivalent (non-scalar) measures of liquidity based on limit order book data. When only the best level of the book is available, however, these liquidity measures become one-dimensional measures of immediacy costs.

\section{DATA}

We use data on a random sample of NYSE-listed stocks. The data is taken from the TAQ Database corresponding to the full year 1996. The initial sample consists of 150 stocks, sampled from the population of 2574 NYSE-listed common stocks in January 1996 using systematic sampling based on market capitalization. ${ }^{2}$ Stocks

${ }^{2}$ With systematic sampling (SS), all stocks have the same probability of being picked up, as with simple random sampling (SRS). However, the final SS-sample is more representative than the SRSsample. SS consists of generating a random number $k$ between 1 and the nearest integer to 2574/150. 
that experience stock-splits and those without quotes and trades registers for more than two consecutive trading days have been eliminated. From the remaining stocks, we take the 25 stocks with the largest mean trade frequency (see the Appendix). Trades not codified as 'regular trades' have been discarded. Only the trades and quotes from the primary market are considered. All quote registers previous to the opening quote, those with bid-ask spreads lower than or equal to zero or quoted depth equal to zero have also been eliminated. Price and quote files are coupled using the so-called 'five seconds rule' (Lee and Ready, 1991).

We break up the trading session into seven time intervals: [9:30-10:00h.), [10:0011:00h.), [11:00-12:00h.), [12:00-13:00h.), [13:00-14:00h.), [14:00-15:00h.), and [15:00-closing]. We use the relative spread weighted by time as the one-dimensional measure of immediacy costs,

$$
R S_{t}=\left(\sum_{j=1}^{l}\left[s_{j} / q_{t}\right] T_{j}\right) / \sum_{j=1}^{l} T_{j}
$$

where $l$ is the number of quote registers in a given time interval, $T_{j}$ is the time (in seconds) between two consecutive quotes, $s_{j}$ is the bid-ask spread and $q_{j}$ is the quote midpoint. To proxy for market depth, we compute a similar measure using the sum of the number of shares offered at the best ask and bid quotes. ${ }^{3}$ We consider the logarithm of these measures in order to reduce the influence of outliers. From the one-dimensional measures, we obtain the bi-dimensional measures in Equations 2 to 6 . The moving average terms in Equation $6, A D_{t-n}^{t-1}$ and $A I C_{t-n}^{t-1}$, are computed considering different time spans (from one week to one month) and weighting criteria. The results are unaffected by such alternative computations. Similarly, the relative variability measure in Equations 5 and $6, w\left(\sigma_{t}^{I C}, \sigma_{t}^{D}\right)$, is computed as a ratio of the historical variance of the one-dimensional measures. Once more, the main conclusions are unaffected by the time spans considered.

Table 1 reports the proportion of ambiguous and unambiguous changes in overall liquidity for each stock in the sample. In median terms, almost $58 \%$ of overall liquidity changes are unambiguous $\left(\zeta_{t}^{D, I C}>0\right)$. This finding is consistent with the negative correlation between immediacy costs and market depth reported by Lee et al. (1993). Indeed, the correlation between the one-dimensional measures of liquidity is statistically negative for $76 \%$ of the sample, with an average Spearman rank correlation of -0.19 . We have also evaluated the average elasticity between immediacy costs and market depth, approximated by $\beta$ in Equation 8 and estimated for each stock by robust regression (Rousseeuw and Leroy, 1987).

$$
\log \left(D_{t}\right)=\alpha+\beta \log \left(I C_{t}\right)+u_{t}
$$

Then, the population is sorted by market capitalization and the stocks selected are those in the $r k$ th positions, where $r=\{1,2, \ldots, 150\}$ (see Som, 1996, pp. 81-90 for details).

${ }^{3}$ We have also considered ex-post liquidity measures, the effective spread weighted by volume to proxy for immediacy costs and the VNET weighted by volume to measure market depth. In addition, the relative spread and the quoted depth have also been computed using the last quotes in each time interval and the effective spread has been computed using an unweighted average. The empirical results for these alternative measures are not reported because of space limitations, but they are available upon request. In general, our main conclusions are independent of the one-dimensional proxies considered. 
Table 1. The ambiguity problem

\begin{tabular}{llllll}
\hline & \multicolumn{3}{l}{ Unambiguous $\left(\zeta_{t}^{D, I C}>0\right)$} & & \\
\cline { 2 - 4 } Stock & Increase & Decrease & No change & Total & $\begin{array}{l}\text { Ambiguous } \\
\left(\zeta_{t}^{D, I C}<0\right)\end{array}$ \\
\hline GE & 23.92 & 26.00 & 2.03 & 51.95 & 48.06 \\
GTE & 25.77 & 28.31 & 1.69 & 55.77 & 44.23 \\
K & 26.22 & 30.61 & 1.69 & 58.52 & 41.47 \\
SLB & 25.49 & 31.68 & 1.74 & 58.91 & 41.08 \\
GRN & 28.36 & 28.87 & 1.69 & 58.92 & 41.08 \\
CMB & 25.27 & 28.70 & 1.29 & 55.26 & 44.74 \\
TXN & 25.10 & 29.15 & 1.29 & 55.54 & 44.46 \\
HPC & 22.68 & 30.95 & 1.69 & 55.32 & 44.68 \\
AGC & 28.31 & 33.48 & 1.69 & 63.48 & 36.52 \\
MAT & 26.17 & 28.87 & 1.69 & 56.73 & 43.28 \\
GP & 26.84 & 28.19 & 1.80 & 56.83 & 43.16 \\
NCC & 28.64 & 29.60 & 1.97 & 60.21 & 39.79 \\
ROH & 25.89 & 29.54 & 1.80 & 57.23 & 42.77 \\
IR & 26.28 & 29.66 & 2.19 & 58.13 & 41.87 \\
OEC & 28.36 & 28.64 & 1.35 & 58.35 & 41.64 \\
EC & 30.16 & 31.34 & 1.97 & 63.47 & 36.52 \\
DDS & 28.64 & 30.61 & 1.86 & 61.11 & 38.89 \\
CEN & 29.26 & 31.34 & 1.74 & 62.34 & 37.65 \\
RYC & 25.15 & 27.97 & 2.98 & 56.1 & 43.89 \\
HM & 26.22 & 28.02 & 1.80 & 56.04 & 43.95 \\
ELY & 26.96 & 28.25 & 1.91 & 57.12 & 42.88 \\
GLM & 25.66 & 28.14 & 1.69 & 55.49 & 44.51 \\
USS & 26.17 & 30.16 & 1.69 & 58.02 & 41.98 \\
RDC & 28.14 & 27.74 & 1.91 & 57.79 & 42.21 \\
ANN & 30.16 & 30.28 & 1.69 & 62.13 & 37.87 \\
Median & 26.22 & 29.15 & 1.74 & 57.79 & 42.21 \\
\hline This & & & & & \\
\hline
\end{tabular}

This table reports the proportion of ambiguous and unambiguous changes in overall liquidity for each stock in the sample.

The estimated elasticity is statistically negative for the $72 \%$ of the sample, with a median $\hat{\beta}=-0.5011(\hat{\alpha}=9.782)$. Nonetheless, Table 1 also shows that an important part of the variations in overall liquidity are ambiguous (42.21\%). Using $\zeta_{t}^{D, I C}(\mu)<0$ to define ambiguity, $45.39 \%$ of overall liquidity changes are ambiguous. These figures highlight the importance of the ambiguity problem.

Table 2 reports the Spearman rank correlations between the bi-dimensional measures proposed in Equations 2 to 6 . The table also distinguishes periods with ambiguous changes in overall liquidity $\left(\zeta_{t}^{D, I C}<0\right)$ from periods with unambiguous changes $\left(\zeta_{t}^{D, I C}>0\right)$. The $B L M_{t}$ and $L R_{t}$ measures are highly correlated, even during periods of ambiguity. However, the volatility causes a difference between the bi-dimensional measures: the median of $B L M_{t}$ is -0.0084 with a standard deviation of 0.1688 , and the median of $L R_{t}$ is 0.0005 with a standard deviation of 1.058 . The 
Table 2. Robust correlations

\begin{tabular}{|c|c|c|c|c|}
\hline & BLM & LR & $\operatorname{BLM}(\mu)$ & $\operatorname{BLM}(\sigma)$ \\
\hline \multicolumn{5}{|l|}{ Total } \\
\hline LR & $\begin{array}{c}0.9839 \\
(0.039)\end{array}$ & & & \\
\hline $\operatorname{BLM}(\mu)$ & $\begin{array}{c}0.5311 \\
(0.046)\end{array}$ & $\begin{array}{c}0.5064 \\
(0.040)\end{array}$ & & \\
\hline $\operatorname{BLM}(\sigma)$ & $\begin{array}{c}0.8327 \\
(0.113)\end{array}$ & $\begin{array}{c}0.8141 \\
(0.114)\end{array}$ & $\begin{array}{c}0.4241 \\
(0.064)\end{array}$ & \\
\hline $\operatorname{BLM}(\mu, \sigma)$ & $\begin{array}{c}0.3987 \\
(0.073)\end{array}$ & $\begin{array}{c}0.3924 \\
(0.072)\end{array}$ & $\begin{array}{c}0.8046 \\
(0.128)\end{array}$ & $\begin{array}{c}0.4894 \\
(0.029)\end{array}$ \\
\hline \multicolumn{5}{|l|}{ Ambiguity } \\
\hline LR & $\begin{array}{c}0.9903 \\
(0.065)\end{array}$ & & & \\
\hline $\operatorname{BLM}(\mu)$ & $\begin{array}{c}0.3872 \\
(0.108)\end{array}$ & $\begin{array}{c}0.3668 \\
(0.050)\end{array}$ & & \\
\hline $\operatorname{BLM}(\sigma)$ & $\begin{array}{c}0.7740 \\
(0.268)\end{array}$ & $\begin{array}{c}0.7689 \\
(0.297)\end{array}$ & $\begin{array}{c}0.1778 \\
(0.110)\end{array}$ & \\
\hline $\operatorname{BLM}(\mu, \sigma)$ & $\begin{array}{c}0.0395 \\
(0.111)\end{array}$ & $\begin{array}{c}0.0555 \\
(0.116)\end{array}$ & $\begin{array}{c}0.3653 \\
(0.174)\end{array}$ & $\begin{array}{c}0.3336 \\
(0.057)\end{array}$ \\
\hline \multicolumn{5}{|l|}{ No ambiguity } \\
\hline LR & $\begin{array}{c}0.9802 \\
(0.019)\end{array}$ & & & \\
\hline $\operatorname{BLM}(\mu)$ & $\begin{array}{c}0.5704 \\
(0.046)\end{array}$ & $\begin{array}{c}0.5611 \\
(0.050)\end{array}$ & & \\
\hline $\operatorname{BLM}(\sigma)$ & $\begin{array}{c}0.8649 \\
(0.043)\end{array}$ & $\begin{array}{c}0.8435 \\
(0.058)\end{array}$ & $\begin{array}{c}0.5373 \\
(0.050)\end{array}$ & \\
\hline $\operatorname{BLM}(\mu, \sigma)$ & $\begin{array}{c}0.5434 \\
(0.051)\end{array}$ & $\begin{array}{c}0.5286 \\
(0.055)\end{array}$ & $\begin{array}{c}0.9337 \\
(0.097)\end{array}$ & $\begin{array}{c}0.5745 \\
(0.032)\end{array}$ \\
\hline
\end{tabular}

This table reports the median Spearman rank correlations among the bi-dimensional liquidity measures in equations (2) to (6). The one-dimensional components are measured in logs. Standard deviations appear in parenthesis.

different versions of $B L M_{t}$ are closer when overall liquidity varies unambiguously with a systematically lower standard deviation.

\section{COMMONALITY IN OVERALL LIQUIDITY}

Recent empirical research has paid attention to cross-firms co-movements in liquidity. Chordia et al. (2000), Huberman and Halka (2001), and Hasbrouck and Seppi (2001) use alternative methodological approaches to report evidence of (generally weak) commonalities in liquidity, that is, common short-term variations in liquidity across firms. These studies presume that liquidity is driven by strong common factors. Liquidity dynamics unconnected with these common determinants may be considered as idiosyncratic variations in liquidity. In this section, we apply the 
methodology proposed by Hasbrouck and Seppi (2001) to our sample of NYSElisted stocks. First, we use principal components analysis to discover the common factors in the bi-dimensional and one-dimensional measures of liquidity formerly discussed. Second, we use canonical correlation analysis to evaluate the correlation between the common factors in the bid-dimensional and one-dimensional measures of liquidity. Finally, we study how much co-variability remains in the bi-dimensional measures of liquidity after accounting for the part associated with the one-dimensional measures of liquidity. If the residual commonality were negligible, that would indicate some informational gain in considering bi-dimensional liquidity measures.

The aim of principal components analysis is to find the most important latent common factors that explain the observed variability within a set of related variables. Thus, the first principal component is the linear projection of the observed variables with the maximum variance or, equivalently, that maximizes the explanatory power of the observed variability up to certain normalization restrictions. Computationally, the coefficients of this linear projection coincide with the eigenvector associated with the largest eigenvalue of the variance-covariance matrix of the standardized variables. Indeed, the eigenvalue $\left(\lambda_{1}\right)$ is the total variation attributable to the principal component. If the matrix of observed variables has full rank, we can obtain as many principal components as variables. In our case, the analysis will be restricted to the first three principal components.

For each liquidity measure, we compute the principal components of the panel formed with the 25 standardized time series. ${ }^{4}$ Table 3-A reports the first three eigenvalues and the variability explained by each principal component. If the 25 time series were uncorrelated, there would be only one eigenvalue $\left(\lambda_{i}=1, \forall i\right)$ with a multiplicity of 25 . Hence, a generally accepted rule of thumb is to neglect all eigenvalues close to unity. The first common factor of all bi-dimensional measures explains $21.59 \%$ (in median) of the total variability of overall liquidity. The second and third principal components, however, are usually negligible. Therefore, most of the common variation seen in overall liquidity is due to a single common factor. For the one-dimensional measures, we report at least two non-negligible principal components that account for $30.68 \%$ and $19.44 \%$ of the total volatility in immediacy costs and market depth, respectively.

Canonical correlation analysis determines the most important latent common factors that explain the covariance between two sets of observed variables. Given two sets of standardized variables, for example $B L M_{t}$ and $R S_{t}$, the first canonical variates are given by the vectors $\left(\alpha^{*}, \beta^{*}\right)$ that maximize $\operatorname{Corr}\left(B L M_{t} \alpha, R S_{t} \beta\right)$. A large

\footnotetext{
${ }^{4}$ Since Hasbrouck and Seppi (2001) are interested in the stochastic sources of variability, they standardize the variables so that the deterministic time-of-day effects are removed. We choose not to differentiate between stochastic and deterministic sources of common variation since we are also interested in discerning whether the deterministic sources of variation of overall liquidity are the same as those of the one-dimensional measures. Therefore, we standardize by simply subtracting the mean and dividing by the standard deviation. Although principal components analysis is sensible to the units in which the variables are measured, the standardization is not strictly necessary since it is equivalent to extracting the eigenvectors and eigenvalues from the correlation matrix instead of the variance-covariance matrix. Nonetheless, standardization facilitates certain comparative analyses.
} 
Table 3. Commonalities in overall liquidity

\begin{tabular}{|c|c|c|c|c|c|c|c|c|c|c|c|c|c|c|}
\hline \multicolumn{3}{|c|}{$\begin{array}{l}\text { Panel A: Principal Components } \\
\text { BLM }\end{array}$} & \multicolumn{2}{|l|}{$\operatorname{BLM}(\sigma)$} & \multicolumn{2}{|l|}{$\operatorname{BLM}(\mu)$} & \multicolumn{2}{|c|}{$\operatorname{BLM}(\mu, \sigma)$} & \multicolumn{2}{|l|}{ LR } & \multicolumn{2}{|l|}{ RS } & \multicolumn{2}{|l|}{ D } \\
\hline & $\lambda_{i}$ & $\begin{array}{l}\text { Variation } \\
\text { explained } \\
(\%)\end{array}$ & $\lambda_{i}$ & $\begin{array}{l}\text { Variation } \\
\text { explained } \\
(\%)\end{array}$ & $\lambda_{i}$ & $\begin{array}{l}\text { Variation } \\
\text { explained } \\
(\%)\end{array}$ & $\lambda_{i}$ & $\begin{array}{l}\text { Variation } \\
\text { explained } \\
(\%)\end{array}$ & $\lambda_{i}$ & $\begin{array}{l}\text { Variation } \\
\text { explained } \\
(\%)\end{array}$ & $\lambda_{i}$ & $\begin{array}{l}\text { Variation } \\
\text { explained } \\
(\%)\end{array}$ & $\lambda_{i}$ & $\begin{array}{l}\text { Variation } \\
\text { explained } \\
\text { (\%) }\end{array}$ \\
\hline First & 5.3996 & 21.5984 & 6.5092 & 26.0369 & 5.5462 & 22.1848 & 4.9214 & 19.6858 & 4.9758 & 19.9031 & 5.4893 & 21.9572 & 2.8873 & 11.5494 \\
\hline Second & 1.1030 & 4.4118 & 1.0121 & 4.0482 & 1.5790 & 6.3158 & 1.2555 & 5.0218 & 1.1190 & 4.4758 & 2.1808 & 8.7231 & 1.9740 & 7.8958 \\
\hline Third & 1.0479 & 4.1915 & 0.9933 & 3.9730 & 1.2036 & 4.8145 & 1.1948 & 4.7793 & 1.0783 & 4.3131 & 1.6188 & 6.4753 & 1.3695 & 5.4778 \\
\hline Cum. & & 30.2017 & & 34.0581 & & 33.3151 & & 29.4870 & & 28.6921 & & 37.1556 & & 24.9230 \\
\hline
\end{tabular}

Panel B: Canonical Correlations

\begin{tabular}{|c|c|c|c|c|c|c|c|c|c|c|}
\hline & \multicolumn{2}{|l|}{ BLM } & \multicolumn{2}{|l|}{$\operatorname{BLM}(\sigma)$} & \multicolumn{2}{|l|}{$\operatorname{BLM}(\mu)$} & \multicolumn{2}{|c|}{$\operatorname{BLM}(\mu, \sigma)$} & \multicolumn{2}{|l|}{ LR } \\
\hline & with RS & with D & with RS & with D & with RS & with D & with $\mathrm{RS}$ & with D & with RS & with D \\
\hline First & 0.7417 & 0.4414 & 0.5507 & 0.5097 & 0.9672 & 0.8267 & 0.8261 & 0.9384 & 0.4463 & 0.6015 \\
\hline Second & 0.6885 & 0.2954 & 0.4998 & 0.4672 & 0.9511 & 0.7788 & 0.8161 & 0.9214 & 0.3145 & 0.5884 \\
\hline Third & 0.6266 & 0.2866 & 0.4705 & 0.4518 & 0.9411 & 0.7070 & 0.6831 & 0.9185 & 0.3004 & 0.5727 \\
\hline
\end{tabular}

Total variation in overall liquidity explained (\%)

\begin{tabular}{|c|c|c|c|c|c|c|c|c|c|c|}
\hline & \multicolumn{2}{|l|}{ BLM } & \multicolumn{2}{|l|}{$\operatorname{BLM}(\sigma)$} & \multicolumn{2}{|l|}{$\operatorname{BLM}(\mu)$} & \multicolumn{2}{|c|}{$\operatorname{BLM}(\mu, \sigma)$} & \multicolumn{2}{|l|}{ LR } \\
\hline & $\mathrm{RS}$ & $D$ & $\mathrm{RS}$ & $D$ & RS & $D$ & $\mathrm{RS}$ & $D$ & $\mathrm{RS}$ & $D$ \\
\hline First & 10.3354 & 7.5177 & 11.0567 & 11.4453 & 49.6786 & 28.6790 & 23.7555 & 41.6196 & 9.1180 & 6.6483 \\
\hline Second & 2.3687 & 0.2664 & 0.5576 & 0.7826 & 10.9716 & 4.5484 & 3.7838 & 5.0328 & 0.8237 & 0.3487 \\
\hline Third & 1.3530 & 0.2201 & 0.4717 & 0.6210 & 3.6465 & 2.1712 & 1.8008 & 4.8156 & 0.7261 & 0.2462 \\
\hline Cum. & 14.0571 & 8.0042 & 12.0860 & 12.8489 & 64.2968 & 35.3985 & 29.3400 & 51.4681 & 10.6678 & 7.2432 \\
\hline
\end{tabular}

Panel A reports the eigenvalues and the total variation in liquidity explained by the first three principal components of each liquidity measure, both one-dimensional and bi-dimensional. For a definition of each variable, see Equations 2 to 6 . Panel B reports the correlation between the bi-dimensional and one-dimensional canonical variates. Additionally, this panel reports a canonical redundancy analysis. The figures represent the proportion of total variation in overall liquidity that is explained by the canonical variates. 
Panel C: Residual Commonality

With Asymmetric Canonical Correlations

\begin{tabular}{|c|c|c|c|c|c|c|c|c|c|c|}
\hline & \multicolumn{2}{|l|}{ BLM } & \multicolumn{2}{|l|}{$\operatorname{BLM}(\sigma)$} & \multicolumn{2}{|l|}{$\operatorname{BLM}(\mu)$} & \multicolumn{2}{|c|}{$\operatorname{BLM}(\mu, \sigma)$} & \multicolumn{2}{|l|}{ LR } \\
\hline & $\lambda_{i}$ & $\begin{array}{l}\text { Variation } \\
\text { explained (\%) }\end{array}$ & $\lambda_{i}$ & $\begin{array}{l}\text { Variation } \\
\text { explained (\%) }\end{array}$ & $\lambda_{i}$ & $\begin{array}{l}\text { Variation } \\
\text { explained (\%) }\end{array}$ & $\lambda_{i}$ & $\begin{array}{l}\text { Variation } \\
\text { explained (\%) }\end{array}$ & $\lambda_{i}$ & $\begin{array}{l}\text { Variation } \\
\text { explained (\%) }\end{array}$ \\
\hline First & 4.5818 & 18.3273 & 5.4955 & 21.9821 & 1.6892 & 6.7568 & 1.5896 & 6.3585 & 4.2890 & 17.1561 \\
\hline Second & 1.0942 & 4.3770 & 1.0374 & 4.1495 & 1.5931 & 6.3722 & 1.5064 & 6.0255 & 1.1433 & 4.5734 \\
\hline Third & 1.0619 & 4.2475 & 1.0327 & 4.1307 & 1.4781 & 5.9125 & 1.3719 & 5.4874 & 1.0939 & 4.3757 \\
\hline Cum. & & 26.9519 & & 30.2624 & & 19.0416 & & 17.8714 & & 26.1052 \\
\hline
\end{tabular}

With Simple Canonical Correlations

\begin{tabular}{|c|c|c|c|c|c|c|c|c|c|c|}
\hline & \multicolumn{2}{|l|}{ BLM } & \multicolumn{2}{|l|}{$\operatorname{BLM}(\sigma)$} & \multicolumn{2}{|l|}{$\operatorname{BLM}(\mu)$} & \multicolumn{2}{|c|}{$\operatorname{BLM}(\mu, \sigma)$} & \multicolumn{2}{|l|}{ LR } \\
\hline & $\lambda_{i}$ & $\begin{array}{l}\text { Variation } \\
\text { explained (\%) }\end{array}$ & $\lambda_{i}$ & $\begin{array}{l}\text { Variation } \\
\text { explained (\%) }\end{array}$ & $\lambda_{i}$ & $\begin{array}{l}\text { Variation } \\
\text { explained (\%) }\end{array}$ & $\lambda_{i}$ & $\begin{array}{l}\text { Variation } \\
\text { explained (\%) }\end{array}$ & $\lambda_{i}$ & $\begin{array}{l}\text { Variation } \\
\text { explained (\%) }\end{array}$ \\
\hline First & 4.9516 & 19.8062 & 5.7809 & 23.1236 & 2.8901 & 11.5605 & 2.0174 & 8.0696 & 4.8844 & 19.5375 \\
\hline Second & 1.1055 & 4.4218 & 1.0363 & 4.1453 & 1.6252 & 6.5009 & 1.5892 & 6.3569 & 1.1461 & 4.5843 \\
\hline Third & 1.0545 & 4.2178 & 1.0049 & 4.0195 & 1.4456 & 5.7825 & 1.5083 & 6.0332 & 1.0872 & 4.3488 \\
\hline Cum. & & 28.4459 & & 31.2883 & & 23.8438 & & 20.4596 & & 28.4705 \\
\hline
\end{tabular}

Panel $\mathrm{C}$ reports the eigenvalues and the total variation in liquidity explained by the first three principal components of the residuals derived from a set of regressions. The dependent variables are the standardized bi-dimensional liquidity measures and the independent variables are the first three canonical variates between the bi-dimensional measures and the one-dimensional proxies of immediacy costs and market depth. We consider two alternative canonical correlation analysis: simple and asymmetric. For a definition of each variable, see Equations 2 to 6 . 
and statistically significant value of this correlation suggests that the common factors in $B L M_{t}$ and $R S_{t}$ are statistically correlated with each other. Table 3-B reports the first three canonical correlations between each bi-dimensional measure and each one-dimensional proxy. As Hasbrouck and Seppi (2001) remark, if $B L M_{t}^{i}$ were perfectly correlated with its own one-dimensional measure, say $R S_{t}^{i}$, but uncorrelated across firms, the correlation would be $\sqrt{1 / 25}=0.2$. Therefore, the canonical correlations reported are, in general, statistically significant. This implies that the commonalities between the bi-dimensional and the one-dimensional measures are statistically interrelated. Nonetheless, notice that the canonical correlations depend on the bi-dimensional proxy chosen. Canonical correlations are stronger for $B L M(\mu)_{t}$ and $B L M(\mu, \sigma)_{t}$, the bi-dimensional proxies that measure overall liquidity changes with respect to the long-run average liquidity level. Table 3-B also reports the proportion of the total variation in each bi-dimensional liquidity measure explained by the first three canonical variates of an asymmetric canonical correlation analysis. This alternative canonical analysis computes the linear projections of a set of variables, say $R S_{t} \beta$, with the highest correlation with each variable $B L M_{t}^{i}$ in another set, $B L M_{t}$, so that it maximizes $\sum_{i=1}^{25} \operatorname{Corr}\left(B L M_{t}^{i}, R S_{t} \beta\right)$. Table 3-B reports a canonical redundancy analysis based on the best three linear projections given by this alternative criteria. As in the previous analysis, we report that the common factors in the one-dimensional measures better explain the variability of $B L M(\mu)_{t}$ and $B L M(\mu, \sigma)_{t}$ than the variability of the other bi-dimensional measures.

Finally, how much co-variability does remain in the bi-dimensional measures after we control for the common factors in the one-dimensional measures? Table 3-C reports the residual commonalities in the bi-dimensional liquidity measures, computed as the first three principal components on the residuals $\left(\varepsilon_{t}^{i}\right)$ of the following regressions,

$$
B_{t}^{i}=\alpha+\sum_{k=1}^{3} \beta_{k} C C_{k, t}^{I C}+\sum_{k=1}^{3} \delta_{k} C C_{k, t}^{D}+\varepsilon_{t}^{i}, \text { for } i=1, \ldots, 25
$$

where $C C_{k, t}^{I C}$ is the $k$ th canonical variate, using either simple or asymmetric canonical correlations analysis, between the some standardized bi-dimensional measure $B_{t}$ and the immediacy costs proxy. Similarly, $C C_{k, t}^{D}$ is the $k$ th canonical variate between $B_{t}$ and the market depth proxy. The first canonical variates are, by construction, the common factors in the one-dimensional measures with the highest power to explain the commonalities in the bi-dimensional measures. Therefore, the strength of the remaining commonality in $\varepsilon_{t}^{i}$ is a measure of the informational value-added in the bi-dimensional proxies of liquidity. Table 3-C shows that the residual co-movements in $\varepsilon_{t}^{i}$ are not negligible. The residual common factors still explain more than $20 \%$ of the total variation of the residuals. The latent factors in the one-dimensional measures explain up to $10 \%$ of the total variation when overall liquidity is measured by $\operatorname{BLM}(\mu)_{t}$ or $B L M(\mu, \sigma)_{t}$. The residual commonality is even stronger when some other bi-dimensional measure proxies for overall liquidity. The results are not remarkably affected by the canonical analysis considered. Hence, barely one-third of the commonality in overall liquidity can be attributed to the common factors in immediacy costs and market depth. 


\section{THE DETERMINANTS OF AN UNAMBIGUOUS CHANGE IN OVERALL LIQUIDITY}

Numerous theoretical studies have examined the impact of market-making costs on market liquidity (O'Hara, 1995). If market-makers, and others suppliers of liquidity, believe that the information asymmetry risk has augmented, they could protect themselves by quoting less depth and/or increasing the bid-ask spread. Similarly, if market-makers are facing an elevated inventory holding risk, they can manage this risk by using both spreads and depths. Whether liquidity responds with ambiguity or not to a variation in market-making costs should depend on the magnitude and the persistence of such a variation. In this way, several empirical studies have shown that spreads widen and depth falls in response to a perceived significant increase in market-making costs surrounding some events, like earning announcements (Lee et al., 1993), dividend announcements (Koski and Michaely, 2000), trading halts (Corwin and Lipson, 2000) and stock splits (Lipson, 1999).

In this section, we use discrete choice models to study the incidence of volatility changes on the probability of observing unambiguous changes in overall liquidity. Chordia et al. (2001) show that the recent volatility, together with the market returns and the deterministic intra-daily patterns, is the main determinant of overall liquidity. An increase in volatility is expected to reduce liquidity because it signals uncertainty about the true value of the stock (Copeland and Galai, 1983; O'Hara and Oldfield, 1986) and it increases the holding risk (Tinic and West, 1972; French and Roll, 1986). Therefore, we expect the probability of an unambiguous liquidity adjustment to increase with the magnitude of the volatility changes. We measure volatility as a weighted mean square distance between the quote midpoint and its median,

$$
\text { Volat }_{t}=\left(\sum_{i=1}^{p}\left[q_{i}-\operatorname{med}_{t}(q)\right]^{2} T_{i}\right) / \sum_{i=1}^{p} T_{i}
$$

where $p$ is the number of midpoint changes, $\operatorname{med}_{t}(q)$ represents the median of the midpoint in period $t$, and $T_{i}$ is the time (in seconds) between two consecutive quotes.

Lee et al. (1993) show that overall liquidity gets worse in response to higher volume. However, they do not control for the simultaneous effect of volatility. Because there is no consensus about what really drives the relationship between trading activity and liquidity (Jones et al., 1994; Chan and Fong, 2000), we will consider alternative measures: $\mathrm{Vol}_{t}$ is the logarithm of the number of shares traded, $\operatorname{Trd}_{t}$ is the logarithm of number of trades completed and $T s z_{t}$ is the logarithm of the average trade size.

To theoretically motivate this analysis, let $U_{t}$ be a binary variable that equals 1 whenever there is an unambiguous change in overall liquidity and 0 otherwise. Assume that there is an underlying (unobservable) response variable $U_{t}^{*}$ defined by the regression relationship

$$
U_{t}^{*}=x_{t}^{\prime} \beta+u_{t}
$$

where $x_{t}$ represents a set of control variables, $\beta$ is a vector of unknown parameters and $u_{t}$ represents an unobservable component. The response variable $U_{t}^{*}$ 
can be understood as the liquidity providers' judgment about market making costs. We assume that liquidity providers evaluate the information-asymmetry and inventory-holding risks by observing the variations in volatility and trading activity $\left(x_{t}^{\prime} \beta\right)$. Whenever they perceive a relevant increase (or decrease) in market making costs, say $U_{t}^{*}>\alpha$, overall liquidity is adjusted by simultaneously altering both immediacy costs and depth in such a way that $\zeta_{t}^{D, I C}>0$. The size of $U_{t}^{*}$ can also be understood as a measure of the quality of market signals. If the market transmits noisy signals, the probability of observing an ambiguous change in liquidity would increase $\left(U_{t}^{*}<\alpha\right)$. While we do not observe $U_{t}^{*}$ directly, we observe the outcome $U_{t}$ such that

$$
U_{t}=I\left(U_{t}^{*}>\alpha\right)
$$

where $I($.$) is an indicator function taking the value 1$ if the condition within parenthesis is satisfied and 0 otherwise. When $u_{t}$ is assumed normally distributed we obtain a Probit model

$$
E\left(U_{t} \mid x_{t}\right)=\operatorname{Pr}\left(U_{t}=1 \mid x_{t}\right)=\Phi\left(x_{t}^{\prime} \beta\right)
$$

where $\Phi(z)$ is the standard normal cumulative distribution function. ${ }^{5}$

We are interested in the magnitude of the change in either volatility or trading activity and not on the sign of this change. Hence, we consider the absolute variation in the different indicators as our set of control variables. The volatility measure in the Probit model will be

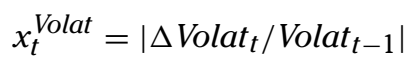

Equivalent measures have been computed for the trading activity measures. Table 4 reports the median empirical correlation matrix between the control variables. All the variables are significantly correlated, suggesting a common information component. The correlation is especially strong among the trading activity measures. In order to control for multicollinearity problems, we first estimate the following Probit model for each control variable $y$ :

$$
\operatorname{Pr}\left(U_{t}=1 \mid x_{t}^{y}\right)=\Phi\left(\beta x_{t}^{y}\right)
$$

Table 5 reports the estimated $\beta$ for each control variable and each stock in the sample. The coefficient is statistically significant and positive in almost all the cases. This finding strongly supports our initial hypothesis: the probability of an unambiguous adjustment in overall liquidity increases with the contemporaneous magnitude of a change in either volatility or trading activity. Notice that this change can be either an increase or a decrease. To evaluate exactly how big this probability change is, we compute the slope of the probability function:

$$
\frac{\partial}{\partial x_{t}^{y}} \Phi\left(\beta x_{t}^{y}\right)=\phi\left(\beta x_{t}^{y}\right) \beta
$$

where $\phi($.$) represents the standard normal density function. This slope depends$ on the level of the explanatory variable. Table 5 reports the slope evaluated at the

${ }^{5}$ If we assume a logistic distribution, we would get a Logit model. Because the cumulative normal distribution and the logistic distribution are very close to each other, except at the tails, we do not obtain very different results using Logit models. 
Table 4. Correlations between the volatility and trading activity proxies

\begin{tabular}{lllll}
\hline & $x_{t}^{\text {Vol }}$ & $x_{t}^{\text {Trd }}$ & $x_{t}^{\text {Tzd }}$ & $x_{t}^{\text {Volat }}$ \\
\hline$x_{t}^{\text {Vol }}$ & 1 & & & \\
$x_{t}^{\text {Trd }}$ & 0.5768 & 1 & & \\
$x_{t}^{\text {Tzd }}$ & 0.5609 & 0.6839 & 1 & 1 \\
$x_{t}^{\text {Volat }}$ & 0.2958 & 0.2350 & 0.2090 & 1 \\
\hline
\end{tabular}

This table reports the median correlation matrix for the time series of the absolute change in volatility and the absolute change in the alternative trading activity proxies. All correlations are significantly different from zero. $\mathrm{Vol}$ is the logarithm of the number of shares traded, Trd is the logarithm of number of trades completed, $T z d$ is the logarithm of the average trade size, Volat is the volatility measure in Equation 10 and $x_{t}^{y}=\left|\Delta y_{t} / y_{t-1}\right|$.

average value of each explanatory variable $\beta \bar{x}^{y}$. Therefore, the figures in Table 5 represent the estimated increase on the probability of an unambiguous liquidity change for an infinitesimal deviation of the explanatory variable evaluated at the mean and extrapolated out. An infinitesimal increase/decrease in market volatility augments the probability of observing an unambiguous liquidity adjustment, in median, by 0.1841 . The impact of an infinitesimal increase in trading activity is particularly larger for the average size (0.332) and the volume traded (0.314).

To evaluate to what extent the previous findings concerning trading activity are explained by the contemporaneous volatility, we have also estimated the following model:

$$
\operatorname{Pr}\left(U_{t}=1 \mid x_{t}^{\text {Volat }}, \tilde{x}_{t}^{y}\right)=\Phi\left(\beta_{1} x_{t}^{\text {Volat }}+\beta_{2} \tilde{x}_{t}^{y}\right)
$$

where $\tilde{x}_{t}^{y}$ is the component of a given trading activity measure that is uncorrelated with $x_{t}^{\text {Volat }}$. We estimate $\tilde{x}_{t}^{y}$ as the residuals of a robust regression of each trading activity measure on $x_{t}^{\text {Volat }}$. Likewise, we have estimated the model (Equation 16) for each trading activity measure $x_{t}^{y}$ :

$$
\operatorname{Pr}\left(U_{t}=1 \mid x_{t}^{y}, \tilde{x}_{t}^{\text {Volat }}\right)=\Phi\left(\beta_{1} \tilde{x}_{t}^{\text {Volat }}+\beta_{2} x_{t}^{y}\right),
$$

where $\tilde{x}_{t}^{\text {Volat }}$ is the component of the volatility measure that is uncorrelated with $x_{t}^{y}$. Table 6 reports the slopes of the probability function evaluated at the mean whenever the corresponding coefficient $\beta_{i}$ for $i=\{1,2\}$ is statistically significant at least at the $10 \%$ level. On the one hand, Table 5 indicates that the variations in volatility and trading activity share some information component. The conditional probability of an unambiguous liquidity adjustment after a variation in either the volatility or the trading activity decreases when we control for commonalities. On the other hand, increases in the activity-adjusted volatility measure $\left(\tilde{x}_{t}^{\text {Volat }}\right)$ are positively correlated with the probability of an unambiguous liquidity adjustment (Table 6-B). Increases in the volatility-adjusted trading measures also influence the probability of unambiguous liquidity movements (Table 6-A). However, $\tilde{x}_{t}^{\mathrm{Vol}}$ is statistically significant at the $5 \%$ level for four stocks only, $\tilde{x}_{t}^{\text {Trd }}$ for seven stocks and $\tilde{x}_{t}^{T s z}$ for thirteen stocks. Therefore, we conclude that, in our sample, the average 
Table 5. The determinants of an unambiguous change in overall liquidity

\begin{tabular}{|c|c|c|c|c|c|c|c|c|}
\hline & \multicolumn{4}{|c|}{ Panel A: Coefficient $(\beta)$} & \multicolumn{4}{|c|}{ Panel B: Slopes of the probability function } \\
\hline & Volat. & Vol. & Trd. & Tsz. & Volat. & Vol. & Trd. & Tsz. \\
\hline GE & $\begin{array}{l}0.1376 * \\
(0.060)\end{array}$ & $\begin{array}{c}0.1565 \\
(0.129)\end{array}$ & $\begin{array}{c}-0.0151 \\
(0.058)\end{array}$ & $\begin{array}{c}0.1319 \\
(0.102)\end{array}$ & 0.0549 & - & - & - \\
\hline GTE & $\begin{array}{l}0.2291 * \\
(0.076)\end{array}$ & $\begin{array}{l}0.6746^{*} \\
(0.211)\end{array}$ & $\begin{array}{c}0.4985^{*} \\
(0.122)\end{array}$ & $\begin{array}{c}0.7574^{*} \\
(0.184)\end{array}$ & 0.0913 & 0.2684 & 0.1976 & 0.3006 \\
\hline K & $\begin{array}{l}0.1948^{*} \\
(0.047)\end{array}$ & $\begin{array}{c}0.7679 * \\
(0.207)\end{array}$ & $\begin{array}{c}0.4269 * \\
(0.119)\end{array}$ & $\begin{array}{c}0.9523^{*} \\
(0.209)\end{array}$ & 0.0775 & 0.3052 & 0.1695 & 0.3776 \\
\hline SLB & $\begin{array}{l}0.2553^{*} \\
(0.048)\end{array}$ & $\begin{array}{l}0.7672^{*} \\
(0.198)\end{array}$ & $\begin{array}{c}0.3428^{*} \\
(0.090)\end{array}$ & $\begin{array}{l}0.8207^{*} \\
(0.178)\end{array}$ & 0.1013 & 0.3048 & 0.1362 & 0.3256 \\
\hline GRN & $\begin{array}{c}0.6356^{*} \\
(0.123)\end{array}$ & $\begin{array}{l}1.0083^{*} \\
(0.158)\end{array}$ & $\begin{array}{c}0.4052^{*} \\
(0.079)\end{array}$ & $\begin{array}{c}0.7199^{*} \\
(0.147)\end{array}$ & 0.2521 & 0.3989 & 0.1603 & 0.2853 \\
\hline CMB & $\begin{array}{c}0.1774 * \\
(0.078)\end{array}$ & $\begin{array}{c}0.4302^{*} \\
(0.158)\end{array}$ & $\begin{array}{c}0.116^{* *} \\
(0.069)\end{array}$ & $\begin{array}{c}0.3449^{*} \\
(0.132)\end{array}$ & 0.0707 & 0.1713 & 0.0465 & 0.1374 \\
\hline TXN & $\begin{array}{l}0.2423^{*} \\
(0.083)\end{array}$ & $\begin{array}{c}0.9368^{*} \\
(0.215)\end{array}$ & $\begin{array}{c}0.3994^{*} \\
(0.111)\end{array}$ & $\begin{array}{c}0.6793^{*} \\
(0.180)\end{array}$ & 0.0965 & 0.3717 & 0.1588 & 0.2700 \\
\hline HPC & $\begin{array}{l}0.0961^{*} \\
(0.039)\end{array}$ & $\begin{array}{l}0.301^{* *} \\
(0.162)\end{array}$ & $\begin{array}{l}0.1811^{*} \\
(0.081)\end{array}$ & $\begin{array}{l}0.3903^{*} \\
(0.142)\end{array}$ & 0.0383 & 0.1198 & 0.0721 & 0.1554 \\
\hline AGC & $\begin{array}{c}0.5717^{*} \\
(0.085)\end{array}$ & $\begin{array}{l}1.1177^{*} \\
(0.175)\end{array}$ & $\begin{array}{c}0.4127^{*} \\
(0.068)\end{array}$ & $\begin{array}{c}0.9217^{*} \\
(0.130)\end{array}$ & 0.2262 & 0.4408 & 0.1629 & 0.3624 \\
\hline MAT & $\begin{array}{c}0.2174 * \\
(0.066)\end{array}$ & $\begin{array}{c}0.5302^{*} \\
(0.207)\end{array}$ & $\begin{array}{l}0.4435^{*} \\
(0.121)\end{array}$ & $\begin{array}{l}0.7001^{*} \\
(0.191)\end{array}$ & 0.0866 & 0.2112 & 0.1764 & 0.2783 \\
\hline GP & $\begin{array}{c}0.6489 * \\
(0.118)\end{array}$ & $\begin{array}{l}0.7345^{*} \\
(0.235)\end{array}$ & $\begin{array}{l}0.6165^{*} \\
(0.137)\end{array}$ & $\begin{array}{l}0.8521^{*} \\
(0.205)\end{array}$ & 0.2573 & 0.2922 & 0.2446 & 0.3384 \\
\hline NCC & $\begin{array}{l}0.7113^{*} \\
(0.080)\end{array}$ & $\begin{array}{l}1.5963^{*} \\
(0.259)\end{array}$ & $\begin{array}{l}0.8305^{*} \\
(0.141)\end{array}$ & $\begin{array}{l}1.2144^{*} \\
(0.219)\end{array}$ & 0.2790 & 0.6285 & 0.3282 & 0.4797 \\
\hline $\mathrm{ROH}$ & $\begin{array}{c}0.4664^{*} \\
(0.116)\end{array}$ & $\begin{array}{c}0.6976^{*} \\
(0.210)\end{array}$ & $\begin{array}{c}0.4214^{*} \\
(0.128)\end{array}$ & $\begin{array}{l}0.7958^{*} \\
(0.200)\end{array}$ & 0.1855 & 0.2774 & 0.1677 & 0.3161 \\
\hline IR & $\begin{array}{l}0.7096^{*} \\
(0.154)\end{array}$ & $\begin{array}{c}0.9269 * \\
(0.289)\end{array}$ & $\begin{array}{c}0.8182^{*} \\
(0.211)\end{array}$ & $\begin{array}{l}1.1652^{*} \\
(0.266)\end{array}$ & 0.2819 & 0.3683 & 0.3250 & 0.4611 \\
\hline OEC & $\begin{array}{l}0.7719^{*} \\
(0.149)\end{array}$ & $\begin{array}{c}0.8849^{*} \\
(0.325)\end{array}$ & $\begin{array}{c}1.041^{*} \\
(0.223)\end{array}$ & $\begin{array}{l}1.0671^{*} \\
(0.268)\end{array}$ & 0.3062 & 0.3521 & 0.4130 & 0.4236 \\
\hline EC & $\begin{array}{l}0.5851 * \\
(0.094)\end{array}$ & $\begin{array}{c}1.81^{*} \\
(0.258)\end{array}$ & $\begin{array}{l}0.9532^{*} \\
(0.138)\end{array}$ & $\begin{array}{l}1.3859^{*} \\
(0.201)\end{array}$ & 0.2318 & 0.7082 & 0.3756 & 0.5445 \\
\hline DDS & $\begin{array}{l}0.8272^{*} \\
(0.143)\end{array}$ & $\begin{array}{c}1.043^{*} \\
(0.231)\end{array}$ & $\begin{array}{c}0.505^{*} \\
(0.112)\end{array}$ & $\begin{array}{l}1.0541^{*} \\
(0.197)\end{array}$ & 0.3275 & 0.4134 & 0.2003 & 0.4171 \\
\hline CEN & $\begin{array}{l}0.8044^{*} \\
(0.089)\end{array}$ & $\begin{array}{r}1.977^{*} \\
(0.336)\end{array}$ & $\begin{array}{l}1.4773^{*} \\
(0.255)\end{array}$ & $\begin{array}{l}1.0651^{*} \\
(0.259)\end{array}$ & 0.3158 & 0.7793 & 0.5831 & 0.4227 \\
\hline RYC & $\begin{array}{l}0.2990^{*} \\
(0.059)\end{array}$ & $\begin{array}{l}0.7001 * \\
(0.177)\end{array}$ & $\begin{array}{c}0.35^{*} \\
(0.082)\end{array}$ & $\begin{array}{c}0.4427^{*} \\
(0.146)\end{array}$ & 0.1187 & 0.2781 & 0.1389 & 0.1762 \\
\hline $\mathrm{HM}$ & $\begin{array}{l}0.3127^{*} \\
(0.084)\end{array}$ & $\begin{array}{c}0.6658^{*} \\
(0.236)\end{array}$ & $\begin{array}{c}0.6396^{*} \\
(0.184)\end{array}$ & $\begin{array}{l}0.7905^{*} \\
(0.230)\end{array}$ & 0.1245 & 0.2650 & 0.2543 & 0.3141 \\
\hline ELY & $\begin{array}{l}0.2621^{*} \\
(0.065)\end{array}$ & $\begin{array}{c}0.7589^{*} \\
(0.240)\end{array}$ & $\begin{array}{l}0.3616^{*} \\
(0.137)\end{array}$ & $\begin{array}{l}0.6505^{*} \\
(0.196)\end{array}$ & 0.1042 & 0.3020 & 0.1968 & 0.3044 \\
\hline
\end{tabular}


Table 5. Continued

\begin{tabular}{|c|c|c|c|c|c|c|c|c|}
\hline & \multicolumn{4}{|c|}{ Panel A: Coefficient $(\beta)$} & \multicolumn{4}{|c|}{ Panel B: Slopes of the probability function } \\
\hline & Volat. & Vol. & Trd. & Tsz. & Volat. & Vol. & Trd. & Tsz. \\
\hline GLM & $\begin{array}{l}0.3050^{*} \\
(0.090)\end{array}$ & $\begin{array}{l}0.7036^{*} \\
(0.207)\end{array}$ & $\begin{array}{l}0.3616^{*} \\
(0.109)\end{array}$ & $\begin{array}{l}0.6505^{*} \\
(0.178)\end{array}$ & 0.1214 & 0.2798 & 0.1439 & 0.2586 \\
\hline USS & $\begin{array}{c}0.4654^{*} \\
(0.071)\end{array}$ & $\begin{array}{c}0.8126^{*} \\
(0.231)\end{array}$ & $\begin{array}{l}0.4999 * \\
(0.109)\end{array}$ & $\begin{array}{l}0.9913^{*} \\
(0.191)\end{array}$ & 0.1841 & 0.3232 & 0.1983 & 0.3929 \\
\hline $\mathrm{RDC}$ & $\begin{array}{c}0.7662^{*} \\
(0.137)\end{array}$ & $\begin{array}{l}0.9535^{*} \\
(0.278)\end{array}$ & $\begin{array}{l}0.8510^{*} \\
(0.182)\end{array}$ & $\begin{array}{c}0.8974^{*} \\
(0.226)\end{array}$ & 0.3035 & 0.3788 & 0.3372 & 0.3558 \\
\hline ANN & $\begin{array}{l}1.3358^{*} \\
(0.183)\end{array}$ & $\begin{array}{l}1.2236^{*} \\
(0.346)\end{array}$ & $\begin{array}{l}1.3321^{*} \\
(0.287)\end{array}$ & $\begin{array}{c}0.9427^{*} \\
(0.253)\end{array}$ & 0.5261 & 0.4857 & 0.5258 & 0.3740 \\
\hline Median & & & & & 0.1841 & 0.3142 & 0.1972 & 0.3320 \\
\hline
\end{tabular}

*Statistically significant at the $5 \%$ level.

** Statistically significant at the $10 \%$ level.

Panel A: Maximum Likelihood estimates of the coefficient $\beta$ in the Probit model (13). Standar deviations are reported in parenthesis. Panel B: Slopes of the probability function of the Probit model (13) evaluated at the mean. $\mathrm{Vol}$ is the logarithm of the number of shares traded, Trd is the logarithm of number of trades completed, $T z d$ is the logarithm of the average trade size and Volat is the volatility measure in Equation 10.

trade size is more useful in predicting unambiguous variations in overall liquidity than the volume traded and the number of trades. Moreover, changes in volatility are far more important than variations in the trading intensity in explaining the unambiguous liquidity adjustments. These findings are consistent with the empirical evidence in Chordia et al. (2001) since volatility determines how does liquidity adjusts more than the trading activity. Additionally, these findings complement the evidence in Lee et al. (1993) since we show that the larger the variation in volatility, the higher the probability of observing immediacy costs and depth movements that complement each other.

Prior analyses do not distinguish between expected and unexpected volatility changes. Nonetheless, unambiguous liquidity adjustments might be more likely when all liquidity providers have a common perception about future volatility levels. That volatility is not uniformly distributed throughout the trading session is a generally known reality. Hence, volatility changes have a component that can be anticipated. If liquidity providers consider this predictable component and their forecasts are similar, unambiguous changes in liquidity are to be expected. In order to provide some intuition about this issue, we decompose $x_{t}^{\text {Volat }}$ into its expected $\left(\tilde{x}_{t}^{\text {Volat }}\right)$ and unexpected $\left(\hat{x}_{t}^{\text {Volat }}\right)$ components using $\mathrm{AR}(1)$ models. Subsequently, we estimate the Probit model

$$
\operatorname{Pr}\left(U_{t}=1 \mid \tilde{x}_{t}^{\text {Volat }}, \hat{x}_{t}^{\text {Volat }}\right)=\Phi\left(\beta_{1} \tilde{x}_{t}^{\text {Volat }}+\beta_{2} \hat{x}_{t}^{\text {Volat }}\right)
$$

and compute the slopes of the probability function. ${ }^{6}$ We obtain that the median impact of an infinitesimal increase in $\hat{x}_{t}^{\text {Volat }}$, extrapolated out and evaluated at the mean, on the probability of an unambiguous change in overall liquidity is

${ }^{6}$ Detailed results are not reported because of the limited space, but they are available upon request from the authors. 
Table 6. Alternative specifications of the Probit model

\begin{tabular}{|c|c|c|c|c|c|c|c|}
\hline & & \multicolumn{3}{|c|}{ Panel A: Volatility-adjusted measures } & \multicolumn{3}{|c|}{ Panel B: Volume-adjusted volatility } \\
\hline & & Vol & Trd & Tsz & Vol & Trd & Tsz \\
\hline \multirow[t]{2}{*}{$\mathrm{GE}$} & $\beta_{1}$ & 0.0549 & 0.0551 & 0.0549 & 0.0634 & 0.0983 & $(0.056)$ \\
\hline & $\beta_{2}$ & - & -0.0667 & - & - & - & - \\
\hline \multirow[t]{2}{*}{ GTE } & $\beta_{1}$ & 0.0911 & 0.0925 & 0.0905 & - & - & - \\
\hline & $\beta_{2}$ & $(0.184)$ & 0.1739 & 0.2538 & 0.2660 & 0.1932 & 0.2981 \\
\hline \multirow[t]{2}{*}{$\mathrm{K}$} & $\beta_{1}$ & 0.0775 & 0.0770 & 0.0757 & 0.0556 & 0.0571 & 0.0470 \\
\hline & $\beta_{2}$ & - & $(0.094)$ & 0.2701 & 0.2997 & 0.1548 & 0.3695 \\
\hline \multirow[t]{2}{*}{ SLB } & $\beta_{1}$ & 0.0968 & 0.0976 & 0.0929 & 0.0866 & 0.0867 & 0.0755 \\
\hline & $\beta_{2}$ & - & - & 0.1804 & 0.3010 & 0.1346 & 0.3223 \\
\hline \multirow[t]{2}{*}{ GRN } & $\beta_{1}$ & 0.2522 & 0.2498 & 0.2468 & 0.1430 & 0.1616 & 0.1683 \\
\hline & $\beta_{2}$ & 0.2677 & 0.1040 & 0.1620 & 0.3953 & 0.1574 & 0.2818 \\
\hline \multirow[t]{2}{*}{$\mathrm{CMB}$} & $\beta_{1}$ & 0.0705 & 0.0707 & 0.0708 & - & - & - \\
\hline & $\beta_{2}$ & $(0.133)$ & - & - & 0.1712 & $(0.046)$ & 0.1367 \\
\hline \multirow[t]{2}{*}{ TXN } & $\beta_{1}$ & 0.0971 & 0.0959 & 0.0954 & - & - & - \\
\hline & $\beta_{2}$ & 0.3495 & 0.1270 & 0.2230 & 0.3708 & 0.1575 & 0.2696 \\
\hline \multirow[t]{2}{*}{ HPC } & $\beta_{1}$ & 0.0383 & 0.0383 & 0.0379 & (0.032) & - & - \\
\hline & $\beta_{2}$ & - & - & $(0.115)$ & $(0.119)$ & 0.0719 & 0.1551 \\
\hline \multirow[t]{2}{*}{ AGC } & $\beta_{1}$ & 0.2238 & 0.2241 & 0.2154 & 0.1505 & 0.1620 & 0.1345 \\
\hline & $\beta_{2}$ & 0.2668 & 0.0951 & 0.2412 & 0.4336 & 0.1615 & 0.3527 \\
\hline \multirow[t]{2}{*}{ MAT } & $\beta_{1}$ & 0.0863 & 0.0865 & 0.0866 & 0.0708 & $(0.051)$ & $(0.051)$ \\
\hline & $\beta_{2}$ & - & 0.1286 & 0.2050 & 0.2110 & 0.1769 & 0.2780 \\
\hline \multirow[t]{2}{*}{ GP } & $\beta_{1}$ & 0.2572 & 0.2499 & 0.2505 & 0.2821 & 0.2105 & 0.2256 \\
\hline & $\beta_{2}$ & - & - & - & 0.2910 & 0.2414 & 0.3394 \\
\hline \multirow[t]{2}{*}{ NCC } & $\beta_{1}$ & 0.2747 & 0.2706 & 0.2706 & 0.2475 & 0.2513 & 0.2538 \\
\hline & $\beta_{2}$ & - & - & - & 0.5915 & 0.3196 & 0.4610 \\
\hline \multirow[t]{2}{*}{$\mathrm{ROH}$} & $\beta_{1}$ & 0.1841 & 0.1833 & 0.1837 & 0.1460 & 0.1476 & 0.1171 \\
\hline & $\beta_{2}$ & - & - & 0.1941 & 0.2743 & 0.1689 & 0.3138 \\
\hline \multirow[t]{2}{*}{ IR } & $\beta_{1}$ & 0.2793 & 0.2781 & 0.2816 & 0.2715 & 0.2343 & 0.1763 \\
\hline & $\beta_{2}$ & - & - & $(0.261)$ & 0.3533 & 0.3220 & 0.4497 \\
\hline \multirow[t]{2}{*}{ OEC } & $\beta_{1}$ & 0.3033 & 0.3032 & 0.3026 & 0.3514 & 0.2216 & 0.2663 \\
\hline & $\beta_{2}$ & - & - & - & 0.3422 & 0.4103 & 0.4268 \\
\hline \multirow[t]{2}{*}{ EC } & $\beta_{1}$ & 0.2319 & 0.2278 & 0.2268 & 0.1288 & 0.1387 & 0.1391 \\
\hline & $\beta_{2}$ & 0.5362 & 0.2731 & 0.3983 & 0.6842 & 0.3738 & 0.5338 \\
\hline \multirow[t]{2}{*}{ DDS } & $\beta_{1}$ & 0.3239 & 0.3158 & 0.3177 & 0.2673 & 0.2625 & 0.2263 \\
\hline & $\beta_{2}$ & - & $(0.085)$ & 0.2220 & 0.4056 & 0.1965 & 0.4134 \\
\hline
\end{tabular}


Table 6. Continued

\begin{tabular}{|c|c|c|c|c|c|c|c|}
\hline & & \multicolumn{3}{|c|}{ Panel A: Volatility-adjusted measures } & \multicolumn{3}{|c|}{ Panel B: Volume-adjusted volatility } \\
\hline & & Vol & Trd & Tsz & Vol & Trd & Tsz \\
\hline \multirow[t]{2}{*}{ CEN } & $\beta_{1}$ & 0.3094 & 0.3081 & 0.3114 & 0.2886 & 0.2862 & 0.3183 \\
\hline & $\beta_{2}$ & - & - & - & 0.7631 & 0.5734 & 0.4310 \\
\hline \multirow[t]{2}{*}{ RYC } & $\beta_{1}$ & 0.1178 & 0.1172 & 0.1171 & 0.0985 & 0.0901 & 0.1126 \\
\hline & $\beta_{2}$ & - & $(0.067)$ & - & 0.2763 & 0.1376 & 0.1754 \\
\hline \multirow[t]{2}{*}{$\mathrm{HM}$} & $\beta_{1}$ & 0.1242 & 0.1244 & 0.1247 & 0.1047 & 0.0854 & 0.0873 \\
\hline & $\beta_{2}$ & - & $(0.148)$ & $(0.190)$ & 0.2613 & 0.2521 & 0.3098 \\
\hline \multirow[t]{2}{*}{ ELY } & $\beta_{1}$ & 0.0946 & 0.0913 & 0.0891 & 0.0858 & 0.0788 & 0.0746 \\
\hline & $\beta_{2}$ & - & $(0.110)$ & 0.1936 & 0.3009 & 0.1986 & 0.3064 \\
\hline \multirow[t]{2}{*}{ GLM } & $\beta_{1}$ & 0.1211 & 0.1207 & 0.1214 & $(0.076)$ & $(0.078)$ & $(0.070)$ \\
\hline & $\beta_{2}$ & $(0.178)$ & $(0.088)$ & 0.1819 & 0.2766 & 0.1424 & 0.2575 \\
\hline \multirow[t]{2}{*}{ USS } & $\beta_{1}$ & 0.1836 & 0.1765 & 0.1743 & 0.1869 & 0.1584 & 0.1484 \\
\hline & $\beta_{2}$ & - & - & 0.1795 & 0.3229 & 0.1929 & 0.3912 \\
\hline \multirow[t]{2}{*}{$\mathrm{RDC}$} & $\beta_{1}$ & 0.2999 & 0.2988 & 0.2980 & 0.3042 & 0.2373 & 0.2608 \\
\hline & $\beta_{2}$ & - & - & - & 0.3662 & 0.3284 & 0.3348 \\
\hline \multirow[t]{2}{*}{ ANN } & $\beta_{1}$ & 0.5234 & 0.5073 & 0.5103 & 0.5884 & 0.4986 & 0.5297 \\
\hline & $\beta_{2}$ & - & - & - & 0.4704 & 0.4612 & 0.3772 \\
\hline \multirow[t]{2}{*}{ Median } & $\beta_{1}$ & 0.1836 & 0.1765 & 0.1743 & 0.1445 & 0.1584 & 0.1391 \\
\hline & $\beta_{2}$ & 0.2668 & 0.1040 & 0.1995 & 0.3119 & 0.1930 & 0.3286 \\
\hline
\end{tabular}

Slopes of the probability function of the Probit model (15) evaluated at the mean, whenever the corresponding coefficient is statistically significant. Panel A: Trading activity measures uncorrelated with the volatility proxy. Panel B: Volatility pair wise uncorrelated with each trading activity proxy. The parenthesis means statistically significant at the $10 \%$ level only. Vol is the logarithm of the number of shares traded, $T r d$ is the logarithm of number of trades completed, $T z d$ is the logarithm of the average trade size and Volat is the volatility measure in Equation (10).

0.1584 . The impact of a similar increase in $\tilde{x}_{t}^{\text {Volat }}$ is 0.3205 . This finding indicates that the probability of an unambiguous liquidity adjustment strongly depends on the expected volatility change. Hence, heterogeneous expectations about future volatility changes among the liquidity providers might explain ambiguity.

\section{CONCLUSIONS}

This paper has dealt with an under-developed topic in microstructure research: the ambiguous changes in overall liquidity. We have characterized ambiguity and discussed several measures that cope with this problem. Our empirical findings show that bi-dimensional liquidity measures are more informative than one-dimensional proxies, even when considered all together: common factors in overall liquidity cannot be fully explained by the common factors in immediacy costs and market depth. Moreover, we have evidenced that the 
volatility changes are positively correlated with the probability of observing a contemporaneous ambiguous change in overall liquidity. We also find that an important part of the incidence of the volatility changes is associated with its expected (deterministic) component. Changes in trading activity also influence the probability of unambiguous liquidity adjustments, especially changes in the average trade size, but to a lesser extent.

The results in this paper suggest further theoretical and empirical research. No theoretical paper exists dealing with how liquidity providers manage market risk using both immediacy costs and market depth. Our results suggest that noisy signals, or equivalently heterogeneous expectations, may be associated with ambiguous liquidity changes. However, a clear signal that generates homogenous interpretations by liquidity providers would induce unambiguous liquidity changes. Moreover, unambiguous liquidity adjustments depend, largely, on the expected volatility changes. Therefore, heterogeneous expectation about future volatility changes should be connected to overall liquidity adjusting unambiguously.

This paper has coped with ambiguity and its determinants. However, these topics deserve further empirical effort. For example, are the determinants of unambiguous liquidity adjustments the same for order-driven markets as for pricedriven markets? Are the determinants of unambiguous liquidity adjustments the same for market makers and specialists as for the limit order book? Is there any intra-daily deterministic pattern in the probability of an unambiguous liquidity adjustment? How does the probability of an unambiguous liquidity adjustment affect the order flow composition? Additionally, we have used volatility and trading activity as proxies of market-making costs. However, it would be interesting to consider direct measures of adverse selection costs, such as the average price impact of trades, and inventory holding costs, such as the inventory levels of the specialists.

Finally, we have considered alternative bi-dimensional measures of liquidity. All these measures, however, depend on a predetermined marginal rate of substitution between immediacy costs and market depth. Moreover, they consider only the information contained in the best ask and bid quotes and do not account for depth improvements. Additional effort should be devoted to finding better bi-dimensional proxies for overall liquidity since our results show that they are superior to directly comparing one-dimensional proxies.

\section{ACKNOWLEDGEMENTS}

Pascual is grateful to the Fundación Caja Madrid for its financial support and Escribano to the Secretaría de Estado de Educación y Universidades PR2003-0305. The authors acknowledge financial support from Spanish DGICYT project \#PB980030. We would like to thank participants at the European Financial Management 1999 Meetings in Paris (France), Foro de Finanzas 1999 in Segovia (Spain), VII Foro de Finanzas 1999 in Valencia (Spain) and the $10^{\text {th }}(\mathrm{EC})^{2}$ Conference on Financial Econometrics 1999 in Madrid (Spain). The authors are especially grateful to Gonzalo Rubio and Daniel Cardona for their helpful suggestions. The contents of this paper are the sole responsibility of the authors. 


\section{APPENDIX}

\section{Sample}

This sample consists of the 25 firms with the highest trading frequency among 150 firms in a larger sample selected by Systematic Sampling. Firms are sorted by mean time between trades.

\begin{tabular}{|c|c|c|c|c|}
\hline $\begin{array}{l}\text { Order by } \\
\text { capitalization }\end{array}$ & Symbol & Name & $\begin{array}{l}\text { Time } \\
\text { between } \\
\text { trades }\end{array}$ & $\begin{array}{l}\text { Time } \\
\text { between } \\
\text { changes } \\
\text { in quotes }^{1}\end{array}$ \\
\hline 1 & $\mathrm{GE}$ & GENERAL ELECTRIC CO & 00:00:26 & 00:00:33 \\
\hline 7 & TXN & TEXAS INSTRUMENTS & 00:00:39 & 00:00:56 \\
\hline 6 & $\mathrm{CMB}$ & CHASE MANHATTAN CO & $00: 00: 43$ & 00:00:35 \\
\hline 2 & GTE & GTE CORP & 00:00:53 & 00:00:58 \\
\hline 4 & SLB & SCHLUMBERGER LTD & 00:01:19 & 00:01:08 \\
\hline 21 & ELY & CALLAWAY GOLF CO & $00: 01: 29$ & 00:01:28 \\
\hline 11 & GP & GEORGIA-PACIFIC CORP & $00: 01: 56$ & 00:01:20 \\
\hline 23 & USS & U. S. SURGICAL CORP & 00:02:01 & 00:01:30 \\
\hline 5 & GRN & GENERAL RE CORP & 00:02:02 & 00:01:35 \\
\hline 20 & HM & HOMESTAKE MINING CO & $00: 02: 14$ & 00:01:56 \\
\hline 8 & $\mathrm{HPC}$ & HERCULES INC & 00:02:20 & 00:02:43 \\
\hline 3 & $\mathrm{~K}$ & KELLOG CO & $00: 02: 22$ & $00: 01: 17$ \\
\hline 22 & GLM & GLOBAL MARINE INC & $00: 02: 24$ & 00:02:20 \\
\hline 10 & MAT & MATTEL INC & $00: 02: 33$ & 00:02:58 \\
\hline 16 & $\mathrm{EC}$ & ENGELHARD CO & 00:02:32 & $00: 01: 56$ \\
\hline 12 & $\mathrm{NCC}$ & NATIONAL CITY CORP & $00: 02: 48$ & 00:02:07 \\
\hline 17 & DDS & DILLARD DEPT STORES CL A & 00:02:48 & 00:01:39 \\
\hline 14 & IR & INGERSOLL-RAND CO & $00: 02: 51$ & 00:01:49 \\
\hline 24 & RDC & ROWAN COMPANIES INC & $00: 03: 13$ & 00:02:40 \\
\hline 9 & $\mathrm{AGC}$ & AMER GEN CORP & 00:03:34 & 00:02:19 \\
\hline 25 & ANN & ANNTAYLOR STORES CORP & 00:03:45 & $00: 02: 33$ \\
\hline 19 & RYC & RAYCHEM CORP & 00:03:52 & $00: 02: 31$ \\
\hline 18 & CEN & CERIDIAN CORP & 00:03:58 & 00:02:46 \\
\hline 15 & $\mathrm{OEC}$ & OHIO EDISON CORP & 00:04:09 & $00: 02: 58$ \\
\hline 13 & $\mathrm{ROH}$ & ROHM AND HASS COMPANY & 00:04:11 & $00: 02: 57$ \\
\hline
\end{tabular}

${ }^{1}$ Change in quoted ask, bid or depth.

\section{REFERENCES}

Ahn, H.-J., Cao, C.Q. and Choe, H. (1996) Tick size, spread and volume, Journal of Financial Intermediation, 5, 2-22.

Bacidore, J., Battalio, R.H. and Jennings, R.H. (2002) Depth improvement and adjusted price improvement on the NYSE, Journal of Financial Markets, 5, 127-258.

Black, F. (1971) Towards a fully automated exchange, part I, Financial Analysts Journal, 27, 29-34. 
Bollen, N.P.B. and Whaley, R.E. (1998) Are 'teenies' better? Journal of Portfolio Management, 25, 10-24.

Chan, K.C. and Fong, W.-M. (2000) Trade size, order imbalance, and the volatility-volume relation, Journal of Financial Economics, 57, 247-73.

Chordia, T., Roll, R. and Subrahmanyam, A. (2000) Commonality in liquidity, Journal of Financial Economics, 56, 3-28.

Chordia, T., Roll, R. and Subrahmanyam, A. (2001) Market liquidity and trading activity, Journal of Finance, 56, 501-30.

Copeland, T.E., and Galai, D. (1983) Information effects on the bid-ask spread, The Journal of Finance, 38, 1457-69.

Corwin, S.A. and Lipson, M.L. (2000) Order flow and liquidity around NYSE trading halts, Journal of Finance, 55, 1771-801.

Engle, R.F. and Lange, J. (2001) Predicting VNET: A model of the dynamics of market depth, The Journal of Financial Markets, 4, 113-42.

French, K.R. and Roll, R. (1986) Stock return variances. The arrival of information and the reaction of traders, Journal of Financial Economics, 17, 5-26.

Glosten, L.R. and Milgrom, P.R. (1985) Bid, ask and transaction prices in specialist market with heterogeneously informed traders, Journal of Financial Economics, 14, 71-100.

Gray, S.F., Smith, T. and Whaley, R.E. (2002) Stock splits: implications for investor trading costs. Working Paper, Duke University.

Goldstein, M.A. and Kavajecz, K.A. (2000a) Eighths, sixteenths, and market depth: changes in tick size and liquidity provision on the NYSE, Journal of Financial Economics, 56, 125-49.

Goldstein, M.A. and Kavajecz, K.A. (2000b) Liquidity provision during circuit breakers and extreme market conditions. Working Paper \#2000-02, NYSE.

Handa, P., Schwartz, R. and Tiwari, A. (1999) Price improvement and price discovery on a primary market, Journal of Portfolio Management, 25(3), 55-64.

Hasbrouck, J. and Seppi, D.J. (2001) Common factors in prices, order flows and liquidity, Journal of Financial Economics, 59, 383-411.

Ho, T. and Stoll, H.R. (1981) Optimal dealer pricing under transactions and return uncertainty, Journal of Financial Economics, 9, 47-73.

Huberman, G. and Halka, D. (2001) Systematic liquidity, Review of Financial Research, 24, 161-79.

Irvine, P., Benston, G. and Kandel, E. (2000) Liquidity beyond the inside spread: measuring and using information in the limit order book. Working Paper, Emory University, Atlanta.

Jones, C.M., Kaul, G. and Lipson, M.L. (1994) Transactions, volume, and volatility, Review of Financial Studies, 7, 631-51.

Jones, C.M. and Lipson, M.L. (2001) Sixteenths: direct evidence on institutional execution costs, Journal of Financial Economics, 59, 253-78.

Kluger, B.D. and Stephan, J. (1997) Alternative liquidity measures and stock returns, Review of Quantitative Finance and Accounting, 8, 19-36.

Koski, J.L. and Michaely, R. (2000) Prices, liquidity, and the information content of trades, Review of Financial Studies, 13, 659-96.

Kumar, R., Sarin, A. and Shastri, K. (1998) The impact of option trading on the market quality of the underlying security: an empirical analysis, Journal of Finance, 53, 717-32.

Kyle, A.S. (1985) Continuos auctions and insider trading, Econometrica, 53, 1315-35.

Kyle, A.S. (1989) Informed speculation with imperfect competition, Review of Economic Studies, 56, 317-56.

Lee, C.M., Mucklow, B. and Ready, M.J. (1993) Spreads, depths, and the impact of earnings information: an intra-daily analysis, The Review of Financial Studies, 6, 345-74. 
Lee, C.M. and Ready, M.J. (1991) Inferring trade direction from intra-daily data, The Journal of Finance, 46, 733-46.

Lipson, M.L. (1999) Stock splits liquidity and limit orders, Working Paper \#99-04, NYSE.

Martínez, M.A., Gonzalo, R. and Tapia, M. (2000) Understanding liquidity: A closer look at the limited order book. Working Paper University Carlos III, 00-52 (12).

O'Hara, M. (1995) Market Microstructure Theory (Cambridge, MA: Blackwell).

O'Hara, M. and Oldfield, G.S. (1986) The microeconomics of market making, Journal of Financial and Quantitative Analysis, 21, 361-76.

Petersen, M.A. and Fialkowski, D. (1993) Posted versus effective spreads: good prices or bad quotes, Journal of Financial Economics, 35, 221-42.

Rousseeuw, P.J. and Leroy, A.M. (1987) Robust Regression and Outlier Detection. New York: John Wiley \& Sons.

Sarin, A., Shastri, K.A. and Shastri, K. (1999) Ownership structure and stock market liquidity. Working Paper, University of Pittsburgh.

Som, R.K. (1996) Practical Sampling Techniques. New York: Marcel Dekker.

Stoll, H.R. (1989) Inferring the components of the bid-ask spread: theory and empirical tests, The Journal of Finance, 19, 115-34.

Subrahmanyam, A. (1991) Risk aversion, market liquidity, and price efficiency, The Review of Financial Studies, 4, 417-42.

Tinic, S.M. and West, R.R. (1972) Competition and the pricing of dealer services in the over-thecounter market, Journal of Financial and Quantitative Analysis, 8, 1707-27. 